\title{
The Efficacy and Safety of Saxagliptin in Haemodialysis Patients
}

\author{
Abdul Halim Abdul Gafor ${ }^{1}$, Azrina Abdul Kadir ${ }^{1}$, Rizna Abdul Cader ${ }^{1}$, Rozita Mohd ${ }^{1}$, \\ Kong Wei Yen ${ }^{1}$, Rohana Abdul Ghani ${ }^{2}$, Shamsul Azhar Shah ${ }^{3}$, Norella C. T. Kong ${ }^{1}$ \\ ${ }^{1}$ Department Nephrology Unit, Department of Medicine, University Kebangsaan Malaysia Medical Centre, \\ Kuala Lumpur, Malaysia \\ ${ }^{2}$ Endocrine Unit, Department of Medicine, University Kebangsaan Malaysia Medical Centre, \\ Kuala Lumpur, Malaysia \\ ${ }^{3}$ Department of Epidemiology and Biostatistics, University Kebangsaan Malaysia Medical Centre, \\ Kuala Lumpur, Malaysia \\ Email: halimgafor@gmail.com
}

Received April 23, 2013; revised May 20, 2013; accepted May 28, 2013

Copyright (C) 2013 Abdul Halim Abdul Gafor et al. This is an open access article distributed under the Creative Commons Attribution License, which permits unrestricted use, distribution, and reproduction in any medium, provided the original work is properly cited.

\begin{abstract}
Introduction: Good glycaemic control without causing excessive hypoglycaemia reduced the risk of macrovascular and microvascular complications in type $2 \mathrm{DM}$ patients on regular haemodialysis (HD). The objectives of this study were to assess the efficacy and safety of add-on saxagliptin to insulin therapy in blood sugar control compared to insulin therapy alone in diabetic patients undergoing HD. Design and Methods: In this prospective open-labelled randomized controlled trial, HD patients with type $2 \mathrm{DM}$ and on stable insulin therapy with $\mathrm{HbA} 1 \mathrm{c} 7 \%-13 \%$ were randomized to receive add-on saxagliptin $2.5 \mathrm{mg}$ once daily to insulin therapy or insulin therapy only for 12 weeks. Results: 24 patients were randomized into each arm equally. Baseline and week-12 serum $\mathrm{HbAlc}$, fructosamine, fasting blood glucose (FBS) and mean self monitoring blood glucose (SMBG) were comparable in the groups. Reduction of HbA1c and mean SMBG were significant in both groups. There was a significant drop in fructosamine levels $(p=0.004)$ and trend of lower FBS ( $p=0.097)$ in add-on saxagliptin group but not in insulin alone group. The incidence of hypoglycaemia was the same in both groups. Conclusion: Add-on saxagliptin to insulin is comparable to insulin therapy alone in blood sugar control in regular HD patients and is safe and generally well tolerated. Add-on saxagliptin group may have more persistent and less fluctuation of glucose control compared to insulin only group.
\end{abstract}

Keywords: Fructosamine; Fasting Blood Sugar; HbA1c; Haemodialysis; Saxagliptin; Type 2 Diabetes Mellitus

\section{Introduction}

Type 2 diabetes mellitus (DM) is a chronic disease characterized by reduced insulin sensitivity and deficient insulin secretion by pancreatic $\beta$-cells $[1,2]$. These defects lead to elevated fasting plasma glucose and postprandial plasma glucose levels, which increase the risk of diabetes-related microvascular and macrovascular complications $[3,4]$.

End stage renal disease (ESRD) is a major problem in both developed and developing countries. In the year 2010, DM was the cause of ESRD in 56\% of all patients accepted for dialysis in Malaysia [5]. The various and opposing effects of ESRD and dialysis can make blood

${ }^{*}$ Conflict of interest statement: The authors have declared that no conflict of interest exists. glucose levels fluctuate widely, placing patients at risk of hyperglycaemia and hypoglycaemia [6]. Uraemia complicates glycaemic control by affecting the secretion, clearance, and peripheral tissue sensitivity of insulin [6]. Haemodialysis (HD) further alters insulin secretion, clearance and resistance as the result of periodic improvement in uraemia, acidosis, and phosphate handling [6].

To our knowledge data are scarce on how diabetes should best be treated in ESRD. The importance of glycaemic control in survival benefits among dialysis patients is still in grey area. A seven years observational study by Oomichi, T. et al. revealed that high HbA1C levels were associated higher mortality rates in diabetic HD patients [7]. Contrary, Williams, M.E. et al. failed to show any correlation between HbA1c with 12-month mortality rate [8]. Therefore it is important to individual- 
ize the HbAlc target in ESRD patients, perhaps becoming less stringent based on age, co morbidity, life expectancy and the presence of risk factors for the occurrence of hypoglycaemia.

In patients with type $2 \mathrm{DM}$ and chronic kidney disease (CKD), antihyperglycaemic treatment options are limited and often associated with undesirable side effects [9-11]. Metformin is contraindicated in patients with CKD because of the increased risk of lactic acidosis. Thiazolidinediones must be used with caution as they tend to increase fluid retention and can be associated with congestive heart failure. Insulin and sulphonylureas increase the risk for hypoglycaemia and often result in weight gain. Furthermore, patients with CKD may be at inherent risk for hypoglycaemia because of effects of renal disease on glucose metabolism including decreased insulin clearance and impaired gluconeogenesis in the kidney $[12,13]$.

Dipeptidyl peptidase-4 (DPP-4) inhibitors and incretin mimetics are newer antihyperglycaemic agents, which may become more frequently used in patients with type 2 DM and CKD [14]. DPP-4 inhibitors slow the degradation and the inactivation of the incretins [15-17]. The incretins account for approximately $50 \%$ to $70 \%$ of the postprandial insulin secretion in healthy individuals [18]. DPP-4 inhibitors increase insulin secretion and decrease glucagon concentration in a glucose-dependent manner, which improves fasting plasma glucose and postprandial glucose [15]. DPP4-inhibitors have a favourable tolerability profile compared with other antidiabetic agents. DPP-4 inhibitors are neutral for the following risks: hypoglycaemia, weight gain, gastrointestinal symptoms, heart failure or oedema, fractures, and drug-drug interactions [19].

The primary objective of this study was to assess the efficacy of add-on saxagliptin to insulin therapy in blood sugar control compared to insulin therapy alone in regular HD patients with type 2 DM. Efficacy were defined by $\mathrm{HbA} 1 \mathrm{C}$, fructosamine, fasting blood sugar (FBS) profiles and mean self monitoring blood glucose (SMBG).

The secondary objective of this study was to assess the safety of add-on saxagliptin to insulin therapy compared to insulin therapy alone in regular haemodialysis patients with type 2 diabetes mellitus. Safety in this study was defined as number of episode of hypoglycaemia. Hypoglycaemia was defined as 1) asymptomatic hypoglycaemia (measured plasma glucose measurement $<3.9 \mathrm{mmol} / 1$ $[20]$ ), 2) documented symptomatic hypoglycaemia (sweating, giddiness, palpitations, confusion, measured plasma glucose measurement $<3.9 \mathrm{mmol} / \mathrm{l}$, without concomitant hypotensive episodes), and 3) severe hypoglycaemia (an event requiring assistance of another person to actively administer carbohydrate, glucagons or resus- citative actions).

\section{Patients and Methods}

This was a prospective open labelled randomized control trial involving patients with type $2 \mathrm{DM}$ undergoing HD. This study was approved by the Research and Ethical Committee of this hospital. Informed and written consents were obtained from all the patients. The inclusion and exclusion criteria were listed in Table 1. The patients were randomized using block of three equally into either insulin only group or add-on saxagliptin to insulin group (saxagliptin $2.5 \mathrm{mg}$ daily + insulin) and treated for 12 weeks.

Patients were provided with a glucometer and diary, and instructed to monitor their fingerstick capillary glucose (DXT) at least three times a week (one fasting and two pre-meals of either pre-lunch or pre-dinner DXT) and record any hypoglycaemic event. Patient's adherence, diaries, glycaemic control and self-monitored blood glucose levels were reviewed at every visit. Insulin titration was done at every visit based on titration schedule to adhere (Table 2). Patients will be reviewed at week 2, 4, 8 and 12. In between the visits, phone calls were made to the HD centres and patients enquiring regarding hypoglycaemic symptoms and DXT readings.

The dosage and duration of treatment were supplied in exact quantities for the 12 weeks study period. Study medication was taken orally, immediately before or with a meal during non-dialysis day. During dialysis day, saxagliptin $2.5 \mathrm{mg}$ was taken after completion of the HD. Compliance and adherence to treatment were assessed by interview and pill counting. Any hypoglycaemic symptom and adverse effects were enquired and recorded.

\section{Statistical Analysis}

Data (non-parametric) was expressed as median and interquartile range. The efficacy profile of saxagliptin versus insulin was analysed using Mann-Whitney $U$ test. The changes of parameters in each group were analysed using Friedman test. The safety profile was analysed using Fischer Exact test. A $p$ value of $<0.05$ was considered as significant. All statistical analyses were performed using the Statistical Package for the Social Sciences version 20.0 (SPSS, Chicago, IL, USA).

\section{Results}

After screening of a total of 540 patients from our HD clinic, 172 diabetic patients were identified and out of this, 24 patients who met the inclusion criteria were recruited and randomized into two groups, insulin only group and add-on saxagliptin to insulin group (12 patients in each arm). 
Table 1. Inclusion and exclusion criteria.

\begin{tabular}{|c|c|}
\hline Inclusion & Exclusion \\
\hline $\begin{array}{l}\text { 1) Age } \geq 18 \text { years old } \\
\text { 2) Type } 2 \text { DM } \\
\text { 3) ESRD undergoing HD } \\
\text { 4) HbAlc: } 7 \% \text { - } 13 \% \\
\text { 5) Stable dose of short acting basal bolus insulin ( } 10-80 \text { units/day) } \\
\text { for at least for } 4 \text { weeks } \\
\text { 6) Willingness to give written consent and comply with the study } \\
\text { protocol }\end{array}$ & $\begin{array}{l}\text { 1) Type } 1 \text { DM } \\
\text { 2) History of diabetic ketoacidosis or hyperosmolar hyperglycaemic } \\
\text { state within the past } 6 \text { months } \\
\text { 3) Secondary cause of diabetes (e.g. steroid-induced) } \\
\text { 4) New York Heart Association stage III/IV congestive heart failure } \\
\text { and or known left ventricular ejection fraction } \leq 40 \% \\
\text { 5) Cardiovascular events including myocardial infarction and unstable } \\
\text { angina within the past } 6 \text { months } \\
\text { 6) Acute kidney injury } \\
\text { 7) History of renal transplant } \\
\text { 8) Anaemia with haemoglobin }<10 \text { g/dl } \\
\text { 9) Any other severe coexisting disease such as, but not limited to, } \\
\text { chronic liver disease, psychiatric disorders, malignancy } \\
\text { 10) Repeated fasting blood sugar (FBS }>15 \text { mmol/l) } \\
\text { 11) Pregnant or lactating women } \\
\text { 12) History of alcohol or drug abuse within the previous year }\end{array}$ \\
\hline
\end{tabular}

Table 2. Insulin adjustment during study period.

\begin{tabular}{cc}
\hline Pre-meal blood glucose (mmol/l) & Action \\
\hline$<4$ & Reduce insulin dose by 2 units \\
$4-7$ & Maintain current dose
\end{tabular}

$>7$ AND no hypoglycaemic episode Increase insulin dose by 2 units

The demographic data and baseline clinical characteristics were tabulated in Table 3. Baseline and end of study parameters between the two groups were tabulated in Table 4. Table 5 revealed the intra-group changes of parameters within each group.

There were 2 patients each group developed hypoglycaemia ( $p=1.00)$. There was no patient developed uncontrolled hyperglycaemia, diabetic ketoacidosis or hyperosmolar hyperglycaemic state in both groups.

\section{Discussion}

Saxagliptin, a new DPP-4 inhibitor has been evaluated in initial therapy of type $2 \mathrm{DM}$ both as a single agent and in combination with other oral antidiabetic agents [18, 21-24]. It is currently available as a once daily oral medication, usually dosed at $5 \mathrm{mg}$ daily [18]. Saxagliptin is rapidly and extensively absorbed after oral dosing and can be taken with or without food. It is excreted by both renal and hepatic pathways. In patients with renal dysfunction evidenced by a creatinine clearance of $\leq 50$ $\mathrm{mL} / \mathrm{min}$, dose reduction to $2.5 \mathrm{mg}$ daily is also recommended [21]. A 4-hour HD session removed $23 \%$ of the saxagliptin dose and therefore it should be taken following HD [22].

Serial $\mathrm{HbA} 1 \mathrm{c}$ measurements are the standard of care in diabetic patients without renal failure. However, factors such as the shorter red life span of red blood cells, iron deficiency, recent transfusion, and use of erythropoietin- stimulating agents can cause underestimation of glucose control in renal failure patients [23]. Despite these limitations, the HbA1c level is considered a reasonable measure of glycaemic control in ESRD [6].

Both groups had comparable baseline and end of study $\mathrm{HbA1c}$ levels. The reductions of HbA1c were significant in both groups. Barnett et al. reported greater reductions in mean HbA1c from baseline to week 24 in the add-on saxagliptin group compared to placebo group in a population with normal kidney function [24]. Nowicki et al. in a subgroup of 36 ESRD patients treated with saxagliptin + insulin/OHA versus placebo + insulin/ OHA reported similar reduction mean $\mathrm{HbA1c}$ between both groups [25]. Unlike our study, not all of the 36 patients were on insulin.

Glycated fructosamine and albumin are other measures of glycaemic control with some advantages over HbAlc in dialysis patients. However, they are not readily available and can be affected by conditions that alter protein metabolism, including ESRD [26-29]. Fructosamine was chosen in this study as it reflects very recent ( 1 - 3 weeks) glycaemic control, therefore potentially lessening the confounding effect of shortened red cell survival or of high red cell turnover seen with HbA1c levels. Fructosamiane levels were the same in between both groups at baseline and at end of study period. Anyhow, we noted that, the reduction of fructosamine levels were only significant in add-on saxagliptin group and not in insulin alone group. As fructosamine can detect shorter duration control of glucose, we suggested that add-on saxagliptin group had more persistent and less fluctuation of glucose control compared to insulin only group.

There was no significant difference in FBS in between the groups. Anyhow, we noted that there was a trend of lower FBS in add-on saxagliptin group. Barnett et al. showed not statistically significant reduction of serum FBS in the add-on saxagliptin group compared to pla- 
Table 3. Comparison of baseline demographic and clinical characteristics between both study groups.

\begin{tabular}{cccc}
\hline & Insulin only & Add-on saxagliptin to insulin & p value \\
\hline Age (in years) & $61(53.75-66)$ & $68(54.5-72)$ & 0.287 \\
Gender(male:female) & $8: 4$ & $6: 6$ & 0.68 \\
Race & $8: 4: 0$ & $9: 1: 2$ & 0.173 \\
(Malay:Chinese:Indian) & $25.5(23.4-28.6)$ & $25(20.7-30.8)$ & 0.619 \\
BMI (kg/m $\left.{ }^{2}\right)$ & $11(92.3 \%)$ & $12(100 \%)$ & 1.00 \\
Baseline Co-Morbidities (\%) & $12(100 \%)$ & $11(92.3 \%)$ & 1.00 \\
Hypertension & $3(25 \%)$ & $4(33.3 \%)$ & 1.00 \\
Dyslipidaemia & $1(8.3 \%)$ & $2(16.7 \%)$ & 1.00 \\
Cerebrovascular disease & $141.5(129-154.3)$ & $141(129.5-149.5)$ & 600 \\
Ischaemic heart disease & $75.5(68.3-82.5)$ & $65(60-82.8)$ & 0.16 \\
SBP (mmHg) & & \\
DBP (mmHg) & &
\end{tabular}

Data are expressed as median (IQR). IQR = interquartile range; BMI: Body Mass Index; SBP: Systolic blood pressure; DBP: Diastolic blood pressure.

Table 4. Baseline and end of study parameters.

\begin{tabular}{|c|c|c|c|c|c|c|}
\hline \multirow{2}{*}{ Characteristic } & \multicolumn{3}{|c|}{ Baseline } & \multicolumn{3}{|c|}{ End of study } \\
\hline & Insulin only & Add-on saxagliptin & $p$ value & Insulin only & Add-on saxagliptin & $p$ value \\
\hline HbA1c (\%) & $8.85(7.1-10.3)$ & $8.45(7.5-10.5)$ & 1.00 & $7.20(5.90-8.70)$ & $7.00(5.80-8.50)$ & 0.56 \\
\hline $\begin{array}{l}\text { Fructosamine } \\
\quad(\text { umol/l) }\end{array}$ & $420(366-487)$ & $482(416-592.3)$ & 0.104 & $366(324-410)$ & $395(351-431)$ & 0.33 \\
\hline $\begin{array}{l}\text { Fasting blood sugar } \\
\qquad(\mathrm{mmol} / \mathrm{l})\end{array}$ & $12.6(10-15.7)$ & $12.6(7.9-19.4)$ & 0.976 & $8.60(6.93-13.58)$ & $7.40(5.50-10.40)$ & 0.43 \\
\hline $\begin{array}{c}\text { Mean SMBG, } \\
(\mathrm{mmol} / \mathrm{l})\end{array}$ & $11.3(8.2-12.7)$ & $11.4(8.5-14)$ & 0.799 & $8.10(6.83-10.40)$ & $8.50(7.30-9.70)$ & 0.97 \\
\hline $\begin{array}{l}\text { Haemoglobin } \\
\qquad(\mathrm{g} / \mathrm{dL})\end{array}$ & $11.95(11.2-13.4)$ & $11.9(10.9-12.3)$ & 0.41 & $11.1(10.4-12.3)$ & $12.1(10.0-13.3)$ & 0.39 \\
\hline Albumin $(\mathrm{g} / \mathrm{L})$ & $41(38.3-43.8)$ & $40.5(38.3-44.3)$ & 1.00 & $40.0(38.3-42.5)$ & $42.0(40.0-46.0)$ & 0.12 \\
\hline $\begin{array}{l}\text { Insulin requirement } \\
\text { (unit)/day }\end{array}$ & $42(28.5-44)$ & $30(21-37.5)$ & 0.128 & $44.0(30.0-58.0)$ & $32.0(24.0-36.0)$ & 0.40 \\
\hline
\end{tabular}

Data are expressed as median (IQR). IQR = interquartile range.

Table 5. Parameters within each group.

\begin{tabular}{|c|c|c|c|c|c|c|c|}
\hline & & Baseline & Week 2 & Week 4 & Week 8 & Week 12 & p value \\
\hline \multirow{2}{*}{$\begin{array}{c}\text { HbAlc } \\
(\%)\end{array}$} & $\begin{array}{l}\text { Insulin only } \\
\text { Add-on }\end{array}$ & $8.85(7.1-10.3)$ & - & $8.15(6.63-10.53)$ & $8.05(7.13-9.13)$ & $7.20(5.90-8.70)$ & 0.046 \\
\hline & $\begin{array}{l}\text { Saxagliptin to } \\
\text { insulin }\end{array}$ & $8.45(7.5-10.5)$ & - & $7.6(6.38-8.83)$ & $8(7.33-9.1)$ & $7.00(5.80-8.50)$ & 0.001 \\
\hline \multirow{2}{*}{$\begin{array}{l}\text { Fructosamine } \\
\text { (umol/l) }\end{array}$} & $\begin{array}{l}\text { Insulin only } \\
\text { Add-on }\end{array}$ & $420(366-487)$ & $416.0(378.8-464.8)$ & $394.5(350.3-441.3)$ & $410(360-473)$ & $366(324-410)$ & 0.092 \\
\hline & $\begin{array}{l}\text { Saxagliptin to } \\
\text { insulin }\end{array}$ & $482(416-592.3)$ & $425.5(383.3-504.8)$ & $454.5(376.5-475.5)$ & $444(374-465)$ & $395(351-431)$ & 0.004 \\
\hline \multirow{2}{*}{$\begin{array}{c}\text { FBS } \\
(\mathrm{mmol} / \mathrm{l})\end{array}$} & $\begin{array}{l}\text { Insulin only } \\
\text { Add-on }\end{array}$ & $12.6(10-15.7)$ & $8.85(7.1-12.9)$ & $9.8(5.6-13.2)$ & $9.05(7.9-12.1)$ & $8.60(6.93-13.58)$ & 0.856 \\
\hline & $\begin{array}{l}\text { Saxagliptin to } \\
\text { insulin }\end{array}$ & $12.6(7.9-19.4)$ & $10.5(6.9-11.8)$ & $8.8(6.9-12.4)$ & $9.4(6.8-12.9)$ & $7.40(5.50-10.40)$ & 0.097 \\
\hline \multirow{2}{*}{$\begin{array}{l}\text { Mean SMBG } \\
(\mathrm{mmol} / \mathrm{l})\end{array}$} & $\begin{array}{l}\text { Insulin only } \\
\text { Add-on }\end{array}$ & $11.3(8.2-12.7)$ & - & $8.4(7.9-11.4)$ & $8.05(8-12.6)$ & $8.10(6.83-10.40)$ & 0.045 \\
\hline & $\begin{array}{l}\text { Saxagliptin to } \\
\text { insulin }\end{array}$ & $11.4(8.5-14)$ & - & $9.4(8.4-11.8)$ & $10.2(8.5-10.8)$ & $8.50(7.30-9.70)$ & 0.025 \\
\hline \multirow{2}{*}{$\begin{array}{l}\text { Insulin } \\
\text { requirement } \\
\text { (unit/day) }\end{array}$} & $\begin{array}{l}\text { Insulin only } \\
\text { Add-on }\end{array}$ & $42(28.5-44)$ & $46(30-49.5)$ & $44(30-56)$ & $42(30-55.5)$ & $44.0(30.0-58.0)$ & $<0.001$ \\
\hline & $\begin{array}{l}\text { Saxagliptin to } \\
\text { insulin }\end{array}$ & $30(21-37.5)$ & $32(28.5-46)$ & $32(26-45)$ & $33(26-45)$ & $32.0(24.0-36.0)$ & 0.039 \\
\hline
\end{tabular}

Data are expressed as median (IQR). IQR = interquartile range . 
cebo in a population of patients with normal kidney function [23]. Nowicki et al. reported an increment of adjusted mean FBS from baseline to week 12 for the saxagliptin group, though the difference was not statistically significant [24]. Although, there was no statistical reduction, we believed there was a possible clinical benefit in add-on saxagliptin group with reduction of median FBS from 12.6 to $7.4 \mathrm{mmol} / \mathrm{l}$.

Both groups had comparable baseline and end of study SMBG. Both groups also showed significantly lower SMBG at the end of study period.

There were statistically significant increments of insulin requirement in both groups. This was necessary to prevent hyperglycaemia as majority of the patients had suboptimal glycaemic control on randomization. There was also possible bias as the investigators were not blinded. However, bias was minimized as the insulin dose titration was to follow strict insulin schedule to adhere. Nevertheless, there were no significant differences in insulin increment in between groups and therefore it did not interfere with the efficacy results.

The incidence of hypoglycaemia was the same in both groups. There was no patient had severe hypoglycaemia which required other persons or medical assistance for administration of glucose. The most common adverse reactions reported in of saxagliptin- treated patients were upper respiratory tract infection, headache, nasopharyngitis and urinary tract infection [18,30,31]. Analysis of pooled data also showed no significant weight gain or effect on lipid profile compared to placebo [18,30-33].

The strength of this study relies on its prospective and randomized controlled trial producing homogenous population of type $2 \mathrm{DM}$ on regular HD. However, this study involved a small size and relatively short duration of study period and therefore we may underestimate the safety and tolerability profile. A larger and longer duration of study may provide answers to its safety and tolerability among our HD patients in the future.

\section{Conclusion}

As a conclusion, add-on saxagliptin to insulin is comparable to insulin therapy alone in blood sugar control in regular haemodialysis patients and is safe and generally well tolerated. Add-on saxagliptin group may have more persistent and less fluctuation of glucose control compared to insulin only group. Thus, saxagliptin may have an important role in the treatment of type 2 DM patients on HD.

\section{Acknowledgement}

We would like to thank the Dean of the Faculty of Medicine, Universiti Kebangsaan Malaysia, for allowing us to publish these data.

\section{REFERENCES}

[1] American Diabetes Association, "Standards of Medical Care in Diabetes - 2010," Diabetes Care, Vol. 33, Suppl. 1, 2010, pp. S11-S61. doi:10.2337/dc10-S011

[2] Z. H. Israili, "Advances in the Treatment of Type 2 Diabetes Mellitus," American Journal of Therapeutics, Vol. 18, No. 2, 2011, pp. 117-152.

doi:10.1097/MJT.0b013e3181afbf51

[3] M. J. Fowler, "Microvascular and Macrovascular Complications of Diabetes," Clinical Diabetes, Vol. 26, No. 2, 2008, pp. 77-82.

[4] D. M. Nathan, J. B. Buse, M. B. Davidson, et al., "American Diabetes Association; European Association for the Study of Diabetes. Medical Management of Hyperglycemia in Type 2 Diabetes: A Consensus Algorithm for the Initiation and Adjustment of Therapy: A Consensus Statement of the American Diabetes Association and the European Association for the Study of Diabetes," Diabetes Care, Vol. 32, No. 1, 2009, pp. 193-203. doi: $10.2337 / \mathrm{dc} 08-9025$

[5] L. Y. Ngo, et al., "18th Report of the Malaysian Dialysis and Transplant Registry All Renal Replacement Therapy in Malaysia," The National Renal Registry, Kuala Lumpur, 2010, pp. 1-3.

[6] K. Shrishrimal, P. Hart and F. Michota, "Managing Diabetes in Hemodialysis Patients: Observations and Recommendations," Cleveland Clinic Journal of Medicine, Vol. 76, No. 11, 2009, pp. 649-655. doi:10.3949/ccjm.76a.09054

[7] T. Oomichi, M. Emoto, T. Tabata, T. Morioka, Y. Tsujimoto, H. Tahara, T. Shoji and Y. Nishizawa, "Impact of Glycemic Control on Survival of Diabetic Patients on Chronic Regular Hemodialysis: A 7-Year Observational Study," Diabetes Care, Vol. 29, No. 29, 2006, pp. 1496 1500. doi: $10.2337 / \mathrm{dc} 05-1887$

[8] M. E. Williams, E. Lacson Jr., M. Teng, N. Ofsthun and J. M. Lazarus, "Hemodialyzed Type I and Type II Diabetic Patients in the US: Characteristics, Glycemic Control, and Survival," Kidney International, Vol. 70, No. 8, 2006, pp. 1503-1509. doi:10.1038/sj.ki.5001789

[9] KDOQI, "KDOQI Clinical Practice Guidelines and Clinical Practice Recommendations for Diabetes and Chronic Kidney Disease," American Journal of Kidney Diseases, Vol. 49, No. 2, 2007, pp. S12-S154. doi:10.1053/j.ajkd.2006.12.005

[10] J. F. Yale, "Oral Antihyperglycemic Agents and Renal Disease: New Agents, New Concepts," Journal of the American Society of Nephrology, Vol. 16, Suppl. 1, 2005, pp. S7-S10. doi:10.1681/ASN.2004110974

[11] N. D. Lubowsky, R. Siegel and A. G. Pittas, "Management of Glycemia in Patients with Diabetes Mellitus and CKD," American Journal of Kidney Diseases, Vol. 50, No. 5, 2007, pp. 865-879. doi:10.1053/j.ajkd.2007.08.012

[12] K. Rave, T. Heise, A. Pfutzner, L. Heinemann and P. T. Sawicki, "Impact of Diabetic Nephropathy on Pharmacodynamic and Pharmacokinetic Properties of Insulin in Type 1 Diabetic Patients," Diabetes Care, Vol. 24, No. 5, 
2001, pp. 886-890. doi:10.2337/diacare.24.5.886

[13] M. Stumvoll, "Glucose Production by the Human Kidney-Its Importance Has Been Underestimated," Nephrology Dialysis Transplantation, Vol. 13, No. 12, 1998, pp. 2996-2999. doi:10.1093/ndt/13.12.2996

[14] D. J. Drucker and M. A. Nauck, "GLP-1R Agonists (Incretin Mimetics) and DPP-4 Inhibitors (Incretin Enhancers) for the Treatment of Type 2 Diabetes," Lancet, Vol. 368, No. 9548, 2006, pp. 1696-1705. doi:10.1016/S0140-6736(06)69705-5

[15] A. A. Tahrani, M. K. Piya and A. H. Barnett, "Saxagliptin: A New DPP-4 Inhibitor for the Treatment of Type 2 Diabetes Mellitus," Advances in Therapy, Vol. 26, No. 3, 2009, pp. 249-262. doi:10.1007/s12325-009-0014-9

[16] D. J. Drucker, "The Role of Gut Hormones in Glucose Homeostasis," Journal of Clinical Investigation, Vol. 117, No. 1, 2007, pp. 24-32. doi:10.1172/JCI30076

[17] A. Barnett, "DPP-4 Inhibitors and Their Potential Role in the Management of Type 2 Diabetes," International Journal of Clinical Practice, Vol. 60, No. 11, 2006, pp. 14541470. doi:10.1111/j.1742-1241.2006.01178.x

[18] J. Rosenstock, C. Aguilar-Salinas and E. Klein, "CV181011 Study Investigators. Effect of Saxagliptin Monotherapy in Treatment-Naive Patients with Type 2 Diabetes," Current Medical Research and Opinion, Vol. 25, No. 10, 2009, pp. 2401-2411. doi:10.1185/03007990903178735

[19] B. J. Goldstein, M. N. Feinglos, J. K. Lunceford, J. Johnson and D. E. Williams-Herman, "Effect of Initial Combination Therapy with Sitagliptin, a Dipeptidyl Peptidase-4 Inhibitor, and Metformin on Glycemic Control in Patients with Type 2 Diabetes," Diabetes Care, Vol. 30, No. 8, 2007, pp. 1979-1987. doi:10.2337/dc07-0627

[20] American Diabetes Association Workgroup on Hypoglycemia, "Defining and Reporting Hypoglycemia in Diabetes," Diabetes Care, Vol. 28, No. 5, 2005, pp. 1245-1249. doi:10.2337/diacare.28.5.1245

[21] Onglyza (Saxagliptin) Full Prescribing Information. http://packageinserts.bms.com/pi/pi_onglyza.pdf

[22] D. Boulton, A. Tang, C. Patel, L. Li, X. H. Xu, E. Frevert and D. Kornhauser, "Pharmacokinetics of the Dipeptidyl Peptidase-4 Inhibitor Saxagliptin in Subjects with Renal Impairment," Endocrine Abstracts, Vol. 20, 2009, p. 357.

[23] M. S. Joy, W. T. Cefali, S. L. Hogan and P. H. Nachman, "Long-Term Glycemic Control Measurements in Diabetic Patients Receiving Hemodialysis," American Journal of Kidney Diseases, Vol. 39, No. 2, 2002, pp. 297-307. doi:10.1053/ajkd.2002.30549

[24] A. H. Barnett, B. Charbonnel, M. Donovan and D. Fleming, "Effect of Saxagliptin as Add-On Therapy in Patients with Poorly Controlled Type 2 Diabetes on Insulin Alone or Insulin Combined with Metformin," Current Medical Research \& Opinion, Vol. 28, No. 4, 2012, pp. 1-12. doi:10.1185/03007995.2012.665046

[25] M. Nowicki, I. Rychlik, H. Haller, M. L. Warren, L.
Suchower and I. G. Nilsson, "Saxagliptin Improves Glycemic Control and Is Well Tolerated in Patients with Type 2 Diabetes Mellitus (T2DM) and Renal Impairment Compared with Placebo," Diabetes, Obesity and Metabolism, Vol. 13, No. 6, 2011, pp. 523-532. doi:10.1111/j.1463-1326.2011.01382.x

[26] E. Lamb, T. R. Venton, W. R. Cattell and A. Dawnay, "Serum Glycated Albumin and Fructosamine in Renal Dialysis Patients," Nephron, Vol. 64, No. 1, 1993, pp. 8288. doi:10.1159/000187283

[27] M. Inaba, S. Okuno, Y. Kumeda, et al., "Osaka CKD Expert Research Group. Glycated Albumin Is a Better Glycemic Indicator than Glycated Hemoglobin Values in Hemodialysis Patients with Diabetes: Effect of Anemia and Erythropoietin Injection," Journal of the American Society of Nephrology, Vol. 18, No. 3, 2007, pp. 896-903. doi:10.1681/ASN.2006070772

[28] C. Constanti, J. M. Simo, J. Joven and J. Camps, "Serum Fructosamine Concentration in Patients with Nephrotic Syndrome and with Cirrhosis of the Liver: The Influence of Hypoalbuminaemia and Hypergammaglobulinaemia," Annals of Clinical Biochemistry, Vol. 29, No. 4, 1992, pp. 437-442.

[29] H. C. Ford, W. C. Lim and M. J. Crooke, "Hemoglobin A1 and Serum Fructosamine Levels in Hyperthyroidism," Clinica Chimica Acta, Vol. 166, No. 2-3, 1987, pp. $317-$ 321. doi:10.1016/0009-8981(87)90435-9

[30] M. Jadzinsky, A. Pfützner and E. Paz-Pacheco, “CV181039 Investigators. Saxagliptin Given in Combination with Metformin as Initial Therapy Improves Glycemic Control in Patients with Type 2 Diabetes Compared with Either Monotherapy: A Randomized Controlled Trial," Journal of Diabetes, Obesity and Metabolism, Vol. 11, No. 6, 2009, pp. 611-622.

doi:10.1111/j.1463-1326.2009.01056.x

[31] R. A. De Fronzo, M. Hissa, A. J. Garber, et al., "Saxagliptin 014 Study Group. The Efficacy and Safety of Saxagliptin When Added to Metformin Therapy in Patients with Inadequately Controlled Type 2 Diabetes on Metformin Alone," Diabetes Care, Vol. 32, No. 9, 2009, pp. 1649-1655. doi:10.2337/dc08-1984

[32] A. R. Chacra, G. H. Tan, A. Apanovitch, S. Ravichandran, J. List and R. Chen, "Saxagliptin Added to a Submaximal Dose of Sulphonylurea Improves Glycaemic Control Compared with Uptitration of Sulphonylurea in Patients with Type 2 Diabetes: A Randomised Controlled Trial," International Journal of Clinical Practice, Vol. 63, No. 9, 2009, pp. 1395-1406. doi:10.1111/j.1742-1241.2009.02143.x

[33] P. Hollander, J. Li, E. Allen and R. Chen, "CV181-013 Investigators. Saxagliptin Added to a Thiazolidinedione Improves Glycemic Control in Patients with Type 2 Diabetes and Inadequate Control on Thiazolidinedione Alone," The Journal of Clinical Endocrinology \& Metabolism, Vol. 94, No. 12, 2009, pp. 4810-4819. doi:10.1210/jc.2009-0550 